\title{
Peran HIMPAUDI Dalam Pengembangan PAUD
}

\author{
J.M. Tedjawati \\ Pusat Penelitian Kebijakan dan Inovasi Pendidikan, Balitbang Kemdiknas
}

\begin{abstract}
Abstrak: Tujuan dari tulisan ini adalah untuk memperoleh data dan informasi tentang peran Himpunan Pendidik dan Tenaga Kependidikan Anak Usia Dini Indonesia (HIMPAUDI) dalam pelaksanaan PAUD, khususnya dalam hal: 1) Mensosialisasikan pentingnya PAUD yang berkualitas; 2) Melakukan pembinaan dan pengembangan organisasi secara berjenjang; 3) Menampung, memperjuangkan dan mewujudkan aspirasi para pendidik dan tenaga kependidikan Anak Usia Dini (AUD); dan 4) Memfasilitasi pengembangan profesi pendidik dan tenaga kependidikan anak usia dini. Temuan analisis tulisan ini yaitu: 1) Peran HIMPAUDI dalam mensosialisasikan program PAUD dilakukan melalui berbagai cara yaitu kegiatan bagi AUD antara lain seminar peningkatan kualitas lembaga PAUD, dan memberikan pengarahan akan persyaratan pendirian yang harus dipenuhi oleh lembaga PAUD; 2) Dalam pembinaan dan pengembangan organisasi, HIMPAUDI telah dilakukan pembentukan pengurus HIMPAUDI dari tingkat provinsi, kabupaten/ kota sampai tingkat kecamatan; 3) HIMPAUDI telah memperjuangkan para pendidik untuk memperoleh insentif, baik yang diterima dari Pemerintah maupun usaha yang dikembangkan oleh HIMPAUDI; dan 4) Peran HIMPAUDI dalam pengembangan profesi pendidik dan tenaga kependidikan AUD telah diwujudkan melalui: (i) Pembukaan program S1 di perguruan tinggi; (ii) Pelatihan dasar bagi pendidik AUD, pelatihan konsep PAUD dan pendekatan pembelajaran AUD; (iii) Pelatihan pengelolaan data online bagi pengurus HIMPAUDI; dan (iv) Seminar pola pembelajaran tematik pada PAUD.
\end{abstract}

Kata Kunci: pendidikan anak usia dini, himpunan pendidik dan tenaga kependidikan anak usia dini Indonesia

Abstract : The purpose of this writing an article is to obtain data and information about the role of HIMPAUDI in the implementation of Early Chilhood Development (ECD), expecially to: 1) promote the importance of qualified $E C D ; 2$ ) conduct training and organizational development in stages, 3) accommodate, promote and realize the aspirations of educators and early age (AUD) child care staff, and 4) facilitate professional development of educators and early childhood education personnel. The findings of this analysis are: 1) the role of HIMPAUDI in socializing early childhood programs done through various ways namely for AUD activities (such as dancing, singing along, gymnastics), seminars on improving the quality of early childhood institutions, and provide guidance about the requirements to be met in establishing early childhood institutions; 2 ) in the organization training and development, HIMPAUDI has made the establishment of HIMPAUDI management in provincial, district and subdistrict level; 3) HIMPAUDI has struggled for educators to get the incentives, both received from the government and businesses developed by HIMPAUDI; and 4) HIMPAUDI role in the development of AUD professional teachers and staff has been realized through: (i) the opening of S1 programs in college; (ii) basic training for AUD educators, training of PAUD concept and AUD learning approach, (iii) Training on online data management for HIMPAUDI management, and (iv) seminars about the thematic pattern of early childhood learning.

Key words: education for early childhood, the community of educator and early childhood educator in Indonesia

\section{Pendahuluan}

Pendidikan Anak Usia Dini (PAUD) sebagai upaya untuk menciptakan sumber daya manusia yang bermutu merupakan tahapan yang sangat strategis yang dilakukan secara bertahap, sistimatis dan menjadi tanggung jawab Pemerintah, masyarakat dan dunia usaha lainnya. PAUD memegang peranan penting dan menentukan bagi sejarah perkembangan anak selanjutnya, sebab merupakan fondasi dasar bagi kepribadian anak.

Sejak anak dilahirkan hingga memasuki pendidikan dasar merupakan masa keemasan 
atau disebut "golden age". Masa ini merupakan masa yang tepat untuk meletakkan dasar-dasar pengembangan kemampuan fisik, bahasa, sosial - emosional, konsep diri, seni, moral dan nalainilai agama, yang bermuara pada pertumbuhan dan perkembangan anak yang sehat, cerdas dan mandiri. Dari aspek pendidikan, stimulasi dini sangat diperlukan guna memberikan rangsangan terhadap seluruh aspek perkembangan anak, yang mencapai: 1) penanaman nilai-nilai dasar (budi pekerti dan agama); 2) sikap (disiplin dan kemandirian); dan 3) pengembangan kemampuan dasar (berbahasa, motorik, kognitif dan social). Pemerintah melalui Presiden Republik Indonesia juga telah mencanangkan pelaksanaan Pendidikan Usia Dini se Indonesia pada 23 Juli 2003 bersamaan dengan puncak hari anak Nasional. Mulai saat ini, setiap kelurahan yang ada di Indonesia didorong untuk memiliki minimal satu PAUD. PAUD merupakan alternatif pemenuhan hak pendidikan selain Taman KanakKanak (TK) atau Taman Pendidikan Alqur'an (TPA).

Undang-Undang Sistem Pendidikan Nasional Nomor 20 tahun 2003 pasal 14 secara tegas dinyatakan bahwa pendidkan anak usia dini adalah upaya pembinaan yang ditujukan kepada anak sejak lahir (0) sampai usia (6) tahun yang dilakukan melalui pemberian rangsangan pendidikan untuk membantu pertumbuhan dan perkembangan jasmani dan rohani agar anak memiliki kesiapan dalam memasuki pendidikan yang lebih lanjut.

Dewasa ini masih banyak anak usia dini yang belum mendapatkan layanan pendidikan anak usia dini. Hal ini disebabkan oleh berbagai kendala diantaranya adalah kurangnya lembaga penyelenggara PAUD, jumlah tenaga pendidik baik dari segi kuantitas maupun kualitasnya. Salah satu program yang dapat memenuhi kendala-kendala tersebut di atas adalah melalui program pelatihan pendidik anak usia dini. Kurangnya sosialisasi kepada masyarakat dalam pelaksanaan program PAUD selama ini menyebabkan pemahaman terhadap pendidikan anak usia dini sangat minim, termasuk kurangnya koordinasi antara pendidik dan tenaga Kependidikan PAUD yang ada di setiap Propinsi, kabupaten/kota, dan kecamatan. Hal ini mengakibatkan pengembangan dan peningkatan jumlah pendidik dan tenaga kependidikan PAUD serta jumlah anak usia dini yang tertampung masih jauh dari jumlah yang diharapkan. Padahal keberadaaan pendidik dan tenaga kependidikan PAUD merupakan salah satu komponen yang sangat penting dari keberhasilan pendidikan anak usia dini. Untuk meningkatkan efektifitas, koordinasi dan sosialisasi program PAUD telah dibentuk HIMPAUDI tingkat Pusat yang dideklarasikan di Batu, Malang - Jawa Timur pada tanggal 31 Agustus 2005. Berdirinya HIMPAUDI adalah untuk membantu pemerintah menangani tugas-tugas yang tidak mungkin dapat dilakukan karena keterbatasan sumber daya manusia. Selain itu terbentuknya HIMPAUDI diharapkan dapat: 1) Menjadi wadah bagi para pendidik dan tenaga kependidikan untuk saling asah, asih dan asuh dalam rangka meningkatkan mutu program pendidikan anak usia dini secara optimal di seluruh Indonesia; dan 2) Mengoptimalkan pemahaman dan pengembangan pengetahuan serta keterampilan tentang program pendidikan anak usia dini yang selama ini dirasa masih kurang.

Permasalahan yang dihadapi saat ini adalah sampai seberapa jauh HIMPAUDI dapat menjalankan tugasnya sebagai suatu organisasi independen yang menghimpun unsur pendidik dan tenaga kependidikan anak usia dini, dan juga bagaimana HIMPAUDI dapat mensosialisasikan PAUD yang berkualitas, melakukan pembinaan serta meningkatkan dan memfasilitasi pengembangan profesi pendidik dan tenaga kependidikan anak usia dini.

Tujuan dari penulisan artikel ini dimaksudkan untuk memperoleh data dan informasi tentang peran HIMPAUDI dalam pelaksanaan PAUD. Secara khusus tujuan penelitian ini adalah untuk memperoleh data dan informasi tentang peran HIMPAUDI dalam: 1) Mensosialisasikan pentingnya PAUD yang berkualitas; 2) Melakukan pembinaan dan pengembangan organisasi secara berjenjang; 3) Menampung, memperjuangkan dan mewujudkan aspirasi para pendidik dan tenaga kependidikan anak usia dini; dan 4) Memfasilitasi pengembangan profesi pendidik dan tenaga kependidikan anak usia dini.

\section{Kajian Literatur Pendidikan Anak Usia Dini}

PAUD (Pendidikan Anak Usia Dini) merupakan 
jenjang pendidikan sebelum jenjang pendidikan dasar yang merupakan suatu upaya pembinaan yang ditujukan bagi anak sejak lahir sampai dengan usia enam tahun yang dilakukan melalui pemberian rangsangan pendidikan untuk membantu pertumbuhan dan perkembangan jasmani dan rohani agar anak memiliki kesiapan dalam memasuki pendidikan lebih lanjut, yang diselenggarakan pada jalur formal, nonformal, dan informal. Lebih lanjut, PAUD merupakan salah satu bentuk penyelenggaraan pendidikan yang menitikberatkan pada peletakan dasar ke arah pertumbuhan dan perkembangan fisik (koordinasi motorik halus dan kasar), kecerdasan (daya pikir, daya cipta, kecerdasan emosi, kecerdasan spiritual), sosio emosional (sikap dan perilaku serta agama) bahasa dan komunikasi, sesuai dengan keunikan dan tahap-tahap perkembangan yang dilalui oleh anak usia dini. Ada dua tujuan mengapa perlu diselenggarakan pendidikan anak usia dini, yaitu: 1) Tujuan utama: untuk membentuk anak yang berkualitas, yaitu anak yang tumbuh dan berkembang sesuai dengan tingkat perkembangannya sehingga memiliki kesiapan yang optimal di dalam memasuki pendidikan dasar serta mengarungi kehidupan di masa dewasa; dan 2) Tujuan penyerta: untuk membantu menyiapkan anak mencapai kesiapan belajar (akademik) di sekolah.

\section{Pengertian, Tugas, dan Fungsi HIMPAUDI}

Pengertian HIMPAUDI. HIMPAUDI adalah suatu organisasi independen yang menghimpun unsur pendidik dan tenaga kependidikan anak usia dini. Pendidik anak usia dini adalah tenaga yang berperan menjadi panutan, pembimbing, pengasuh dan fasilitator bagi anak usia dini. Pendidik bagi anak usia dini disebut pendidik (guru). Sedangkan tenaga kependidikan adalah pengelola, pemerhati, pakar, praktisi dan masyarakat umum lainnya yang melaksanakan program PAUD (http://www.scribd.com/doc/ 9628183/HIMPAUDI-ADARTpdf).

Tugas Pokok dan Fungsi (Tupoksi) HIMPAUDI. Ada empat tugas pokok HIMPAUDI yaitu: (i) Mensosialisaikan pentingnya pendidikan anak usia dini yang berkualitas kepada semua lapisan masyarakat; (ii) Melakukan pembinaan dan pengembangan organisasi secara berjenjang; (iii)
Menampung, memperjuangkan dan mewujudkan aspirasi para pendidik dan tenaga kependidikan anak usia dini; (iv) Memfasilitasi pengembangan profesi pendidik dan tenaga kependidikan anak usia dini. Fungsi HIMPAUDI yaitu: (i) Mempersatukan para pendidik dan tenaga kependidikan anak usia dini di Indonesia; dan (ii) Meningkatkan kualitas pendidikan anak usia dini sesuai dengan konsep dasar pembinaan tumbuh kembang anak secara holistik.

Dalam AD pasal 17 diungkapkan tentang struktur organisasi HIMPAUDI berjenjang dari tingkat pusat, tingkat wilayah, tingkat daerah, dan tingkat cabang. Struktur organisasi tersebut dijabarkan dalam ART pasal 8 yaitu struktur pengurus Pusat untuk tingkat Nasional, struktur pengurus Wilayah untuk tingkat Provinsi, struktur pengurus Daerah untuk tingkat Kabupaten/Kota, dan struktur pengurus Cabang untuk tingkat Kecamatan. Pada pasal 21 AD diungkapkan tentang pengangkatan, pengesahan, dan pelantikan. Pengurus Pusat HIMPAUDI disahkan oleh Musyawarah Nasional (Munas) dan pelaksanaannya diatur dalam ART. Pengurus wilayah, daerah, dan cabang HIMPAUDI diangkat, disahkan, dan dilantik oleh pengurus setingkat lebih tinggi dan pelaksanaanya diatur dalam ART.

\section{Aktifitas HIMPAUDI}

HIMPAUDI mempunyai aktifitas/kegiatan yang telah ditetapkan dalam Tata Kerja HIMPAUDI (http://www.scribd.com/doc/9628179/HimpaudiTata-Kerja). Sehingga setiap HIMPAUDI di daerah harus mengikuti langkah kegiatan yang telah ditetapkan dalam Tata Kerja tersebut. Adapun program kegiatan tersebut disusun melalui tahapan sebagai berikut: (i) Perencanaan: Setelah HIMPAUDI terbentuk serta disahkan maka untuk selanjutnya pengurus serta anggota organisasi bersama-sama membuat perencanaan program kerja dan sosialisasi sesuai kondisi dan kebutuhan masing-masing daerah; (ii) Pelaksanaan: Perencanaan yang sudah dibuat kemudian diimplementasikan atau dilaksanakan melalui berbagai kegiatan yang menganut prinsipprinsip prioritas, efektifitas dan efisiensi; (iii) Monitoring dan Evaluasi: Pelaksanaan kegiatan yang sedang berjalan harus dimonitor untuk melihat apakah sesuai dengan perencanaan yang 
dibuat. Setelah kegiatan selesai harus dievaluasi untuk mengukur keberhasilan kegiatan. Hasil evaluasi dapat dijadikan masukan bagi perencanaan program berikutnya; dan (iv) Pelaporan: Untuk mempertanggungjawabkan kegiatan yang telah dilaksanakan harus membuat laporan. Laporan dibuat sebagai bentuk transparansi kepada berbagai pihak terkait. Sehingga akuntabilitas dan kredibilitas himpunan dapat dijaga dengan baik. Pelaporan berisi antara lain: laporan kegiatan dan pertangungjawaban keuangan.

\section{Temuan Penelitian dan Pembahasan}

\section{Mensosialisasikan pentingnya PAUD yang berkualitas}

Berbagai upaya untuk mensosialisasikan PAUD telah dilakukan oleh HIMPAUDI baik di tingkat Pusat, propinsi, kabupaten/kota maupun kecamatan. Dalam sosialisasi PAUD tersebut dilakukan berbagai kegiatan, yang seringkali berkaitan dengan Hari Anak Nasional atau Hari Pendidikan Nasional atau Jambore PAUD. Presiden RI telah mencanangkan pelaksanaan PAUD seIndonesia, bersama dengan puncak Hari Anak Nasional. Tentu sudah saatnya masyarakat bahumembahu mengembangkan PAUD, agar terwujud pendidikan berkualitas. Sebagai contoh: (i) HIMPAUDI Wonosobo dengan kegiatan senam pinguin 1000 anak PAUD (http://www.kabupaten wonosobo.com/index.php? modul= berita\&cat $=$ BDaerah\&catid $=232713204224$ ); (ii) HIMPAUDI kota Malang dengan kegiatan menyanyi bersama, membaca syair, menari, dan fashion show (http://ksupointer.com/2010/partisipasiHIMPAUDI-di-festival-malang-kembali-v); (iii) HIMPAUDI kabupaten Kutai Kertanegara dengan pertandingan futsal (http://humas.kutaikarta negarakab.go.id/index.php/ read/HIMPAUDIkukar-rayakan-hari-anak-nasional/); (iv) HIMPAUDI Kota Pangkal Pinang dengan kegiatan baca puisi, senam ceria dan tari kreasi baru yang merupakan ciptakan para guru ( http://cetak. bangkapos.com/serumpunsebalai/read/ 6718.html); (v) HIMPAUDI kota Bekasi dengan kegiatan pembuatan kreasi kupu-kupu dari playdough (http://skbnews.com/HIMPAUDI); dan (vi) HIMPAUDI kabupaten Lampung Barat (http:// lampungbarat.go.id/index.php?option= com content\&task=view\&id=1083\&Itemid $=142$ ). Tujuan utama dari kegiatan ini adalah dapat meningkatkan kesadaran orang tua, masyarakat dan lembaga/organisasi terhadap pentingnya pembinaan pendidikan anak usia dini. Selain itu juga untuk meningkatkan dukungan, partisipasi dan peran serta masyarakat terhadap pengembangan penyelenggaraan dan pembinaan sebagai program PAUD dan akses dan mutu layanan PAUD serta pencitraan publik terhadap PAUD. Bagi anak sendiri kegiatan yang dilakukan HIMPAUDI ini berguna: (i) Untuk menguji kemampuan anak dalam mengembangkan talenta, anak dapat terus melatih aspek kemampuannya, baik motorik maupun psikologis, melatih anak menuju kemandirian dan kedewasaan; (ii) Pemberian stimulus pengayaan pengetahuan anak, dan pengembangan potensi serta daya kreativitas anak; (iii) Anak jadi lebih berani dan tidak takut, dalam menghadapi berbagai persoalan, serta lebih kreatif dalam menyikapi berbagai permasalahan; (iv) Pembentukan sikap mental dan kepribadian anak yang berlandaskan pada nilai-nilai ajaran agama yang akan menjadi pondasi bagi perkembangan watak dan kepribadian anak sampai mereka dewasa.

Peran HIMPAUDI dalam rencana Pemerintah akan menerapkan kebijakan PAUD secara holistic integratif pada tahun 2009 sehingga seluruh penyelenggaraan PAUD di Tanah Air dapat berpedoman pada suatu acuan yang sama (http:/ Lwww.nttonlinenews.com/ntt/index.php?view= article $\% 3 \mathrm{~B} \&$ catid $=37 \% 3 \mathrm{Apendidikan \& id=1090 \% 3}$ Apendidikan-anak-usia-dini-secara-holistikditerapkan $2009 \&$ format $=$ pdf \& option $=$ com content). Dalam PAUD holistik nantinya terdiri dari berbagai tenaga ahli, baik bidang pendidikan, kesehatan, psikolog, ilmu gizi dan sebagainya. Pemerintah Daerah akan menjadi pelaksana utama penyelenggaraan PAUD holistik bekerjasama dengan HIMPAUDI dan organisasi wanita seperti PKK dan sebagainya. Peran HIMPAUDI dengan Pemerintah tersebut dilakukan pada saat acara dialog interaktif dalam rangka HUT ke-3 HIMPAUDI tahun 2008.

HIMPAUDI telah menumbuhkan lembagalembaga PAUD hampir di tiap desa. Sebagai contoh kota Pekalongan, Jawa Tengah yang 
hanya terdiri atas empat kecamatan, kini sudah berdiri 96 lembaga PAUD (kurang lebih 90\% dari wilayah Kota Pekalongan sudah ada PAUD) (http:/ Lm.suaramerdeka.com/index.php/read/cetak/ 2009/05/14/63446 tanggal 14 Mei 2009). Begitupula yang terjadi di kota Serang mengalami peningkatan yang cukup pesat dari tahun sebelumnya (tahun 2009), yakni dari sekitar 60 lembaga meningkat menjadi 185 lembaga (http:/ /mediapendidikan.com/lembaga-paud-meningkatdi-kota-serang-banten/).

Peran HIMPAUDI dalam mensosialisasikan PAUD termasuk peningkatan kualitas lembaga PAUD, telah dilakukan oleh HIMPAUDI Bojonegoro dengan mengadakan seminar "Peningkatan Kualitas Management Lembaga menghadapi Akreditasi PAUD" dengan dihadiri sekitar 500 peserta yang berasal dari Forum PAUD, Dharma Wanita, PKK, Penilik PLS, seluruh pengurus dan Anggota Himpunan Pendidik Anak Usia Dini (http:/ Lpnfi-bojonegoro.com/2010/02/23/pelantikanpengurus-HIMPAUDI-dan-seminar-peningkatankualitas manajemen-lembaga $L$ ). Tujuan kegiatan seminar memantapkan gerakan HIMPAUDI dalam perannya mendidik anak PAUD dan meningkatkan kualitas lembaga PAUD itu sendiri.

Temuan hasil penelitian yang dilakukan oleh Pusat Penelitian Kebijakan (Penelitian tentang Kontribusi Pemerintah Daerah dalam Perintisan dan Penguatan PAUD, tahun 2010) menunjukkan bahwa umumnya HIMPAUDI berperan serta dalam pendirian dan pendidiknya. Peran HIMPAUDI dalam pendirian suatu lembaga PAUD di wilayahnya hanya sebatas memberikan pengarahan akan persyaratan pendirian yang harus dipenuhi oleh lembaga PAUD; dan memantau pemenuhan persyaratan yang telah dilakukan lembaga PAUD. Menurut HIMPAUDI syarat pendirian lembaga PAUD yakni diantaranya harus adanya pengelola, warga belajar, pendidik, tempat pembelajaran, akte notaries, rekomendasi dari UPT dinas kecamatan (UPTD), dukungan dari masyarakat setempat, izin operasional dari dinas pendidikan (disdik) kabupaten/kota. Masalahnya belum semua lembaga PAUD sampel memenuhi syarat pendirianya, terutama untuk memenuhi akte notaris.

\section{Melakukan pembinaan dan pengembangan organisasi secara berjenjang}

Pengembangan HIMPAUDI di tingkat kecamatan telah dilakukan oleh HIMPAUDI Pusat dan kabupaten/kota yaitu dengan terbentuknya pengurus HIMPAUDI di tingkat kabupaten/kota dan kecamatan. Sesuai dengan ART maka pelantikan pengurus HIMPAUDI di tingkat kabupaten/kota dilakukan oleh ketua HIMPAUDI Pusat (Dra. Gusnawrta Fasli, M.Pd). Sedangkan pengurus HIMPAUDI di tingkat kecamatan dilakukan oleh pengurus HIMPAUDI di tingkat kabupaten/kota, walau demikian seringkali HIMPAUDI kabupaten/kota mengundang pengurus HIMPAUDI Pusat. Beberapa HIMPAUDI yang telah melakukan pelantikan dan pengukuhan pengurus HIMPAUDI antara lain: HIMPAUDI Propinsi Jawa Barat (pelantikan dan pengukuhan Pengurus HIMPAUDI tingkat Provinsi pertama kali di Inodnesia tahun 2005) (http://himpaudijawabarat.or.id/read/uncategorized/11/kilas-balikhimpaudi/), HIMPAUDI Kabupaten Musi Banyuasin (pelantikan dan pengukuhan Pengurus HIMPAUDI Kabupaten Musi Banyuasin periode 2010-2014) (http://www. beritaindonesia.co.id/daerah/ berprestasi-di-tengah-kesederhanaan), dan HIMPAUDI tingkat Kecamatan se Kota Bogor (pelantikan dan pengukuhan Pengurus HIMPAUDI tingkat Kecamatan Se kota Bogor periode 20092010) (http://www. kotabogor.go.id/index. php?option=com_content\&task $=$ view\&id $=4965 \&$ Itemid=1). Menurut pengurus HIMPAUDI kota Bogor, keberadaan PAUD di tengah masyarakat memiliki peranan besar dalam memberikan kesempatan yang seluas-luasnya bagi setiap anak untuk mengenyam pendidikan usia dini. Hal itu terutama ditujukan bagi anak-anak dari keluarga yang memang mengalami kesulitan atau memiliki akses sama sekali terhadap berbagai lembaga PAUD. Selain itu pada saat ini HIMPAUDI kota Bogor yang sudah berdiri empat tahun (di tahun 2009) dengan jumlah pendidik PAUD mencapai 792 orang atau 99 persen itu sudah mengikuti pelatihan HIMPAUDI Kota Bogor. Diharapkan, masyarakat harus lebih banyak dilibatkan untuk berkecimpung dalam aktivitas PAUD, terutama, mereka yang memiliki kemampuan dan potensi khusus di bidang pendidikan dan pengembangan anak. Selain itu, HIMPAUDI 
harus berusaha menjalin kerjasama dengan berbagai lembaga lain yang dapat membantu meningkatkan kapasitas para relawan, yang menjalankan peran dan fungsinya sebagai pengasuh pendidik anak-anak di setiap PAUD.

Telah diterbitkan 'MAUDI' suatu Majalah bagi pendidik, tenaga kependikan serta orang tua yang peduli terhadap PAUD, yang dhilakukan oleh HIMPAUDI Jawa Tengah melalui Bidang HUMAS (http://himpaudijateng.wordpress.com/humas/). Majalah ini telah berhasil dicetak hingga edisi ke 3, dan mendapat respon yang sangat positif baik dari Direktorat, HIMPAUDI Kabupaten/ Kota maupun pembaca pada umumnya. Keberhasilan ini juga didukung oleh banyaknya pihak terutama pendidik yang berkenan menyumbangkan buah pikir mereka, melalui karya tulis yang mereka kirimkan kepada Tim Redaksi MAUDI. Prinsip berbagi ilmu dan pengalaman bagi sesama, merupakan motivasi utama. Kedalaman materi yang ringan, enak dibaca namun bermanfaat bagi para pembacanya. Mengupas secara populer berbagai permasalahan yang sering dihadapai orang tua, dan para pendidik ditambah berbagai kegiatan yang menyenangkan dan dapat dilakukan bersama anak-anak juga disajikan secara menarik dalam majalah ini.

Dilakukan Musyawarah Nasional ke II dengan jumlah peserta 250 orang yang terdiri atas pengurus pusat, pimpinan wilayah, sekretaris cabang, dan peninjau. Munas ke dua ini dilaksanakan 8 Agustus 2010. Pada saat Munas tersebut, telah dihasilkan pembentukan HIMPAUDI di tingkat propinsi di Indonesia dan harapannya dapat menyentuh kabupaten/kota, bahkan kecamatan di seluruh Indonesia. Menurut ketua pengurus HIMPAUDI Pusat biasanya sebuah perhimpunan membutuhkan waktu lama untuk berkembang, tetapi HIMPAUDI baru Munas II telah menjangkau seluruh provinsi.

Acara Pemilihan Mitra PAUD 2010 tingkat nasional diselenggarakan dengan tujuan agar HIMPAUDI di tingkat kabupaten/kota/kecamatan berlomba secara berjenjang untuk berkompetensi dalam perencanaan progam, kegiatan HIMPAUDI, eksistensi lembaga PAUD di daerahnya, tenaga pendidik dan siswa yang dimiliki di daerahnya. Pemilihan Mitra PAUD ini diselenggarakan direrektorat PAUD bekerjasama dengan
HIMPAUDI Pusat lima tahun sekali. Tahun 2010 dimenangkan HIMPAUDI kota Malang (http:// www.portalmalang.web.id/profil/mike-s-arifinsosok-di-balik-suksesnya-HIMPAUDI-raih-juara-inasional.html diunduh 29 Juli 2010).

Pemantapan strategi organisasi HIMPAUDI telah dilakukan oleh HIMPAUDI propinsi Jawa Barat dengan menerapkan visi HIMPAUDI (http:// HIMPAUDI-jawabarat.or.id/read/news/49/ pemantapan-strategi-HIMPAUDI-jabar/). Pemantapan peran HIMPAUDI sebagai organisasi profesi, menuntut kepahaman dan teladan para pengurus terhadap profesi pendidik yang diembannya. Pembelajar, harus terwujud nyata dengan bukti karya nyata yang menjadi kontribusi pembangunan bangsa, dari para pendidik anak usia dini Jawa Barat yang unggul, profesional, akhlak karimah, akan lahir anak-anak kita yang sehat, ceria, berakhlak mulia. Kesabaran, kasih sayang dan pemahaman tumbuh kembang sangat perlu kita pahami. Pemberdayaan HIMPAUDI, tantangan agar organisasi menjadi hidup dan berdaya. Bagaimana menciptakan iklim agar pendidik dan tenaga kependidikan senang dan menikmati serta mensyukuri sebagai pembelajar, agar potensi-potensi dirinya berkembang dan bermanfaat bagi anak usia dini yang menjadi amanahnya dan bagi sesama teman seprofesi serta masyarakatnya. Membuka wawasan pendidik dan tenaga kependidikan anak usia dini, suatu upaya yang diharapkan dapat meningkatkan motivasi untuk maju dan berdaya guna. Memberikan dukungan moral dan doa, bagian yang kami yakini akan saling memberdayakan kita bersama. Konsolidasi, memelihara dinamika organisasi dengan komitmen dan integritas menegakkan kebenaran moral dan keadilan. Keindahan akan kesadaran berorganisasi, dan kesabaran menghadapi tantangan, sangatlah menggetarkan. Menghasilkan aneka pembelajaran yang dapat dihayati dan semakin termaknai. Kemampuan menuntaskan dinamika organisasi merupakan keberhasilan para pemimpin HIMPAUDI di berbagai daerah.

Peran HIMPAUDI dalam menghimpun tenaga pendidik PAUD mengalami peningkatan cukup maju. Salah satunya terjadi di HIMPAUDI Jawa Barat, dimana pada tahun 2010 anggota pendidik PAUD yang tergabung dalam HIMPAUDI mencapai 
9.877 orang, meningkat lebih dari sepuluh kali dari tahun 2006 yang hanya berjumlah 652 orang (http://bataviase.co.id/node/417530). Peningkatan pendidik PAUD ini kurang sebanding dengan jumlah anak yang mendapat pelayanan PAUD. Sebanyak 44,5 persen dari 4-559-000 anak berusia 0 sampai 6 tahun di Jawa Barat tidak mendapatkan pelayanan PAUD. Ada beberapa faktor yang menyebabkan masih banyaknya anak usia dini yang belum mendapatkan layanan pendidikan. Faktor yang paling utama, yaitu tingkat pengetahuan masyarakat yang minim mengenai pentingnya pendidikan anak pada usia dini. Informsi mengenai pentingnya pendidikan anak pada usia dini terbatas di kalangan tertentu, yaitu menengah ke atas dan masyarakat berpendidikan tinggi. Hal ini tidak disadari sepenuhnya oleh orang tua, padahal pendidikan pada usia dini sangat penting. Sementara faktor lainnya, yaitu tingkat sosial ekonomi masyarakat yang rendah. Selain itu pemerintah juga belum maksimal dalam melakukan penanganan pendidikan anak usia dini. Bahkan, anggaran pemerintah sangat terbatas untuk menyediakan honor bagi tenaga PAUD. Oleh karenanya Pembina HIMPAUDI Jawa Barat menghendaki pendidik PAUD harus menjalin komunikasi yang cukup baik dengan orang tua anak tersebut. Diharapkan hubungan baik antara orang tua dan tenaga pendidik ini bisa memberikan hasil yang maksimal dalam PAUD.

\section{Menampung, memperjuangkan dan mewujudkan aspirasi para pendidik dan tenaga kependidikan anak usia dini}

Pengurus HIMPAUDI di tingkat Pusat dan kabupaten/kota, memperjuangkan para pendidik untuk memperoleh insentif. Salah satu upaya perolehan insentif bagi pendidik, dilakukan oleh HIMPAUDI Jawa Tengah melalui pendataan penerima insentif (tahun 2009) (http://paud pandanwangi.wordpress.com/2007/12/08/ pelatihan-pengelolaan-data-online-bagiHIMPAUDI-se-jawa-tengah/). Syarat penerima insentif adalah: (i) bukan PNS; dan (ii) telah bekerja selama 1 tahun secara terus menerus di PAUD Non Formal. Selain itu HIMPAUDI Jawa Barat mendirikan usaha koperasi yang diharapkan dapat memberi ketenangan dapat berkontribusi nyata mendanai operasional HIMPAUDI Jawa
Barat, walau belum mensejahterahkan pendidik AUD.

\section{Memfasilitasi pengembangan profesi pendidik dan tenaga kependidikan anak usia dini}

Salah satu upaya yang telah dilakukan HIMPAUDI selama ini adalah telah dibukanya program Strata Satu (S1) PAUD di perguruan tinggi, sebagai wujud wacana dari Workshop HIMPAUDI Tingkat Nasional pada tanggal 17 - 19 Juni 2007 di Bandung. Gelar S1 PAUD ini merupakan salah satu standar minimal bagi pendidik PAUD (Permendiknas Nomor 58 tahun 2009). Berikut diuraikan berbagai kegiatan yang telah dilakukan HIMPAUDI dalam rangka meningkatkan profesi pendidik dan tenaga kependidikan AUD.

Pelatihan dasar pendidik AUD yang dilakukan HIMPAUDI bekerjasama dengan direktorat Pendidikan dan Kependidikan dari Ditjen PMPTK dan direktorat PAUD dari Ditjen Pendidikan Luar Sekolah (tahun 2006). Tujuan pelatihan ini yaitu untuk: 1) Memenuhi kekurangan jumlah tenaga pendidik AUD; 2) Meningkatkan mutu tenaga AUD; dan 3) Merencanakan, melaksanakan, dan mengevaluasi program kegiatan bermain pada anak dengan benar. Dalam pelatihan ini dikembangkan empat kompetensi yang harus dimiliki pendidik AUD yaitu: 1) Kompetensi Pedagogi: Memiliki kemampuan menerapkan konsep tentang perkembangan anak, konsep dasar PAUD, konsep bermain, evaluasi perkembangan anak, dan sumber belajar; 2) Kompetensi Kepribadian: Memiliki kemampuan menerapkan etika sebagai pendidik AUD; 3) Kompetensi Sosial: Memiliki kemampuan berkomunikasi dan berinteraksi dengan lingkungan social; dan 4) Kompetensi Profesional: Memiliki kemampuan mendidik AUD dengan menerapkan berbagai pendekatan. Selain itu HIMPAUDI dari beberapa propinsi telah melakukan pelatihan mengenai konsep PAUD dan pendekatan pembelajaran AUD, antara lain dari HIMPAUDI Bengkalis (http:// bengkalis.go.id/sajian_berita.php? link_ atirebdi=682), HIMPAUDI Jawa Tengah (http:// m.suaramerdeka. com/index. php/read/cetak/ 2009/05/14/63446), dan HIMPAUDI Garut (http:/ (paudnaelulmuna. com/search/HIMPAUDI+garut). Pelatihan yang dilakukan HIMPAUDI Bengkalis membahas materi tentang penyusunan Menu 
Pembelajaran Generik (kurikulum PAUD nonformal), berbagai pelatihan (metode Beyond Center and Circle Times/BCCT, dongeng, gerak dan lagu, dan pembuatan APE dari bahan limbah), penyusunan/penerbitan berbagai pedoman/ acuan (Pedoman Penyelenggaraan TPA, KB, dan Pos PAUD). Sedangkan HIMPAUDI Jawa Tengah revitalisasi program pembelajaran, yakni merefresh program pembelajaran sistem beyond centre and circle time (BCCT) yang selama ini telah diterapkan. Dengan cara itu, lembaga-lembaga PAUD yang baru bisa segera menyesuaikan, sedangkan lembaga yang lama lebih memantapkannya. Semua itu bertujuan untuk lebih mengokohkan HIMPAUDI dalam setiap gerak dan langkahnya. Lebih spesifik lagi, yang ingin dicapai oleh organisasi itu di antaranya meningkatkan proses pembelajaran anak, meningkatkan tumbuh kembang anak secara optimal, meningkatkan kompetensi anak dan tenaga pendidik serta meningkatkan kesejahteraan semua anggota organisasi. HIMPAUDI Garut mengajarkan lukisan dengan jari (finger painting). Bermain coret-coret sangat digemari anak-anak apalagi jika menggunakan jari-jari mereka. Beraneke kreasi coretan indah bisa dibuat dari lukisan dengan jari ini (finger painting). Dan untuk lebih amannya cat untuk finger painting ini bisa dibuat sendiri dirumah, tanpa harus menggunakan cat yang dijual ditoko-toko.

Pelatihan pengelolaan data online bagi pengurus HIMPAUDI. Sebagian besar tenaga pendidik PAUD belum mengenal dunia internet (bagaimana rendahnya tingkat pemanfaatan teknologi informasi untuk mendukung perkembangan PAUD di Indonesia). Pelatihan tersebut telah dilakukan oleh HIMPAUDI Jawa Tengah (tahun 2007) (http://paudpandanwangi. wordpress.com/2007/12/08/pelatihanpengelolaan-data-online-bagi-HIMPAUDI-sejawa-tengah/). Tanggapan dari anggota HIMPAUDI adalah: (i) Sebaiknya tiap HIMPAUDI kecamatan diberi software pendataan, yang kemudian pengurus dari kecamatan menginput data anggotanya, dan kemudian dikirim kepada propinsi; (ii) Pelatihan itu WAJIB diutamakan buat Ketua dan Sekertaris dari tingkat Provinsi, Kabupaten dan Kecamatan sebab orang pertama yang terlibat dalam masalah/informasi baik dari dalam /luar dan Wajib punya komputer/laptop dalam satu atap.

Seminar tentang pola pembelajaran tematik pada PAUD dilakukan atas kerjasama HIMPAUDI Kabupaten Kebumen dengan Dinas DIKPORA dan GOPTKI. Pembelajaran tematik sendiri menyediakan keluasan dan kedalaman implementasi kurikulum, dan menawarkan kesempatan yang sangat banyak pada siswa/anak didik untuk memunculkan dinamika dalam pendidikan. Sehingga siswa/anak didik secara produktif dapat menjawab pertanyaan yang dimunculkan sendiri dan memuaskan rasa ingin tahu dengan penghayatan secara alamiah tentang dunia di sekitar mereka. Penerapannya memang tidaklah mudah, memerlukan perencanaan dan pengorganisasian yang handal agar dapat berhasil dengan baik. Setidaknya, dalam merancang pola pembelajaran tematik pada anak usia dini, ada lima hal yang perlu diperhatikan yaitu: 1) memilih tema, 2) mengorganisir tema, 3) mengumpulkan bahan dan sumber, 4) merancang kegiatan dan proyek, dan 5) mengimplementasikan pada satuan pelajaran.

Peran HIMPAUDI dalam pengelolaan, pendampingan dan pembinaan pendidik PAUD dikemukakan dalam temuan hasil penelitian yang dilakukan oleh Pusat Penelitian Kebijakan (Penelitian tentang Kontribusi Pemerintah Daerah dalam Perintisan dan Penguatan PAUD, tahun 2010). 1) Peran HIMPAUDI dalam pengelolaan lembaga PAUD, khususnya dalam pengadaan pelatihan, workshop, seminar yang bertujuan untuk meningkatkan dan mengembangkan kompetensi pengelola dan pendidik PAUD. Dalam pengelolaan lembaga PAUD, HIMPAUDI melakukan kerjasama dengan pihak lain seperti pihak PKK setempat, forum PAUD, dinas pendidikan setempat, LSM (misal PLAN Indonesia), puskesmas, Pos Yandu, SKB, IDI dan penilik PLS. Dampak kontribusi HIMPAUDI dalam pengelolaan lembaga PAUD terlihat positif, khususnya guna meningkatkan sumber daya manausia (pengelola dan pendidik) lembaga PAUD yang bersangkutan maupun dalam manajemen lembaga PAUD tersebut. Oleh karena HIMPAUDI telah menjadi wadah bagi pendidik dan pengelola PAUD, sehingga kepentingan pendidik dan pengelola tidak terabaikan. Bahkan HIMPAUDI juga mengadakan sosialisasi pengenalan akan 
pentingnya PAUD kepada para orangtua, masyarakat, mengadakan kegiatan lomba bagi AUD, melakukan pendataan lembaga PAUD. 2) Pada peran sebagai pendamping pendidik dan lembaga PAUD, belum seluruh HIMPAUDI melakukan pendampingan tersebut karena keterbatasan dana dalam pendampingan. Bagi HIMPAUDI yang pernah melakukan pendampingan, biasanya melakukan pendampingan lembaga PAUD pada masa penguatan lembaga tersebut. Adapun pihak/unsur lain yang terlibat dalam pendampingan, seperti forum PAUD, dinas pendidikan, PKK, UPT dinas kecamatan (UPTD), Penilik PLS. 3) Sebagian besar HIMPAUDI telah melakukan pembinaan pendidik dan tenaga pengelola PAUD. Jika ada HIMPAUDI yang belum melakukannya, maka hal ini dikarenakan HIMPAUDI tersebut baru terbentuk di daerah sampel. Pihak/unsur lain yang terlibat dalam pembinaan, seperti PKK, SKB,LSM (seperti PLAN Indonesia), penilik PLS, dinas pendidikan dan kesehatan, di mana pada umumnya pembinaan dilakukan minimal 3 kali setahun. Adapun bentuk pembinaan yang dilakukan berupa pelatihan, seminar, pelatihan dan workshop. Kegiatan ini diadakan melalui kerjasama dengan pihak dinas pendidikan setempat (disdik kabupaten/kota), HIMPAUDI tingkat provinsi.

\section{Simpulan dan Saran Simpulan}

Peran HIMPAUDI dalam mensosialisasikan program PAUD telah dilakukan dengan berbagai cara dan umumnya dikemas dalam bentuk kegiatan bagi anak usia dini seperti senam, menyanyi bersama, membaca syair/puisi, menari, pembuatan kreasi kupu-kupu dari plaudough sampai dengan pertandingan futsal. Kegiatan ini merupakan sarana bagi pengembangan talenta AUD termasuk pengembangan potensi dan daya kreativitas anak, pengayaan pengetahuan anak, serta melatih kemampuan motorik dan psiskologis . Dengan atraksi yang ditunjukkan oleh anak-anak tersebut, menyadarkan bagi orangtua dan masyarakat terhadap pentingnya pembinaan dan dukungan terhadap penyelenggaraan PAUD. Sedangkan bagi pendidik AUD kegiatan tersebut merupakan kesempatan untuk meningkatkan kemampuannya dalam menciptakan kreasi tarian, nyanyian, syair dan sebagainya. Selain kegiatan bagi anak, HIMPAUDI juga melakukan sosialisasi program PAUD melalui seminar peningkatan kualitas lembaga PAUD, dan memberikan pengarahan akan persyaratan pendirian yang harus dipenuhi oleh lembaga PAUD.

Dalam pembinaan dan pengembangan organisasi, HIMPAUDI telah melakukan pembentukan pengurus HIMPAUDI dari tingkat provinsi, kabupaten/kota sampai tingkat kecamatan. Dengan terbentuknya HIMPAUDI ini berdampak pada semakin bertambahnya jumlah tenaga pendidik PAUD yang telah bergabung. Untuk meningkatkan kinerja bagi HIMPAUDI, telah dilakukan lomba secara berjenjang untuk berkompetensi dalam perencanaan program, kegiatan HIMPAUDI, eksistensi lembaga PAUD di daerahnya, tenaga pendidik dan siswa yang dimiliki di daerahnya. Lomba ini memberi semangat bagi pendidik agar potensi-potensi dirinya berkembang dan bermanfaat bagi anak usia dini, serta berbagi ilmu dan pengalaman bagi sesama pendidik AUD. Selain lomba, berbagai usaha telah dilakukan HIMPAUDI antara lain penerbitan majalah bagi pendidik, tenaga kependidikan serta orangtua dan diharapkan memberi semangat bagi pendidik untuk mengembangkan buah pikir melalui karya tulis.

Dalam menjalankan tugasnya untuk memperjuangkan dan mewujudkan aspirasi para pendidik, HIMPAUDI telah memperjuangkan para pendidik untuk memperoleh insentif, walau jumlah insentif yang diterima dari pemerintah masih kurang dari yang diharapkan. Oleh karenanya berbagai usaha telah dilakukan HIMPAUDI antara lain dengan pendirian kewirausaha dalam bentuk koperasi untuk mendanai operasional HIMPAUDI dan memberi ketenangan dalam berusaha (walau belum dapat mensejahterahkan pendidik).

Peran HIMPAUDI dalam pengembangan profesi pendidik dan tenaga kependidikan AUD telah diwujudkan dengan berbagai upaya yaitu (i) Telah dibukanya program S1 di perguruan tinggi yang merupakan bentuk wacana yang telah dicetuskan dalam Workshop HIMPAUDI tahun 2007; (ii) Pelatihan dasar bagi pendidik AUD, pelatihan konsep PAUD dan pendekatan pembelajaran AUD; (iii) Pelatihan pengelolaan data online bagi pengurus HIMPAUDI; (iv) Seminar 
pola pembelajaran tematik pada PAUD. Semua bentuk kegiatan tersebut dilakukan HIMPAUDI dengan kerjasama dengan pihak lain seperti pihak PKK setempat, forum PAUD, dinas pendidikan setempat, LSM (misal PLAN Indonesia), puskesmas, Pos Yandu, SKB, IDI dan penilik PLS. Melalui pelatihan dan seminar tersebut, kepentingan pendidik dan pengelola tidak terabaikan dalam meningkatkan mutu PAUD.

\section{Saran}

Atas dasar simpulan di atas disarankan: 1) Dukungan dari anggota HIMPAUDI untuk terus menerus mengupayakan sosialisasi program PAUD dalam berbagai bentuk upaya, dengan melibatkan masyarakat (yang memiliki kemampuan dan potensi khusus di bidang pendidikan dan pengembangan anak) dan berbagai lembaga lain yang dapat membantu meningkatkan kapasitas para relawan, yang menjalankan peran dan fungsinya sebagai pengasuh pendidik anak-anak di setiap PAUD; 2) Kesadaran bagi para pendidik untuk bergabung dalam HIMPAUDI dan juga menjalankan kinerja dan tugas HIMPAUDI. Melalui HIMPAUDI, para pendidik dapat mengikuti pelatihan, workshop, dan seminar yang berguna untuk mengembangkan potensi-potensi dirinya yang bermanfaat bagi AUD dan dapat berbagi ilmu dan pengalaman bagi sesama pendidik; dan 3) Dukungan dari pemerintah (penilik PLS) dan pihak lain seperti PKK, Pos Yandu, dalam menjalankan tugas dan fungsi HIMPAUDI berkaitan dengan usaha peningkatan anak usia dini.

\section{Daftar Pustaka}

Bappenas. 2006. Studi Kebijakan: Pengembangan Anak Usia Dini Yang Holistik dan Terintegrasi. Jakarta: Bappenas.

Bappenas. 2009. Strategi Nasional Pengembangan Anak Usia Dini Holistik-Integratif. Jakarta: Kemneg Perencanaan Pembangunan Nasional.

Direktorat PAUD. 2002. Acuan Menu Pembelajaran pada Pendidikan Anak Dini Usia (Menu Pembelajaran Generik). Jakarta: Depdiknas.

Direktorat PAUD. 2004. Bahan Pelatihan: Lebih Jauh tentang Sentra dan Saat Lingkaran. Jakarta: Depdiknas.

Direktorat PAUD. 2006. Pedoman Penerapan Pendekatan "Beyond Centers and Circle Time (BCCT)/ Pendekatan Sentra dan Lingkaran dalam Pendidikan Anak Usia Dini. Jakarta: Depdiknas.

Direktorat PAUD. 2009. Pedoman Pemberian Bantuan Bagi Forum Pendidikan Anak Usia Dini dan Himpaudi. Jakarta: Depdiknas

Direktorat PAUD. 2010. Pedoman Teknis Penyelenggaraan Pos PAUD. Jakarta: Kemdiknas.

http://www.scribd.com/doc/9628183/HIMPAUDI-ADARTpdf. Anggaran Dasar (AD) dan Anggaran Rumah Tangga (ART) Himpunan Pendidik Dan Tenaga Kependidikan Anak Usia Dini (Himpaudi) http://www.scribd.com/doc/9628179/Himpaudi-Tata-Kerja. Tata Kerja HIMPAUDI

http://www.kabupatenwonosobo.com/index.php? modul=berita\&cat=BDaerah\&catid=232713204224. 1000 Anak Paud Ikut Senam Pinguin di Alun-Alun

http://ksupointer.com/2010/partisipasi-HIMPAUDI-di-festival-malang-kembali-v

Partisipasi HIMPAUDI di Festival Malang Kembali V

http://humas.kutaikartanegarakab.go.id/index.php/read/HIMPAUDI-kukar-rayakan-hari-anaknasional/. HIMPAUDI Kutai Kertanegara Rayakan Hari Anak Nasional

http://cetak.bangkapos.com/serumpunsebalai/read/6718.html. HIMPAUDI Gelar Porseni http://skbnews.com/HIMPAUDI. HIMPAUDI Kota Bekasi Bersama Managemen Bekasi Square. http://lampungbarat.go.id/index.php?option=com content\&task=view\&id=1083\&Itemid =142.

Pendidikan anak usia dini (PAUD) "Kunci Suksesnya Pembangunan Bangsa"

http://www.nttonlinenews.com/ntt/ index.php?view $=$ article\%3B\&catid =37\%3Apendidikan\&id $=1090 \% 3$ Apendidikan-anak-usia-dinisecara-holistik-diterapkan-2009\&format=pdf\&option=com content. Pendidikan Anak Usia Dini Secara Holistik Diterapkan 2009 
http://m.suaramerdeka.com/index.php/read/cetak/2009/05/14/63446 tanggal 14 Mei 2009. Revitalisasi Program Pembelajaran

http://mediapendidikan.com/lembaga-paud-meningkat-di-kota-serang-banten/. Lembaga PAUD meningkat di kota Serang-Banten

http://pnfi-bojonegoro.com/2010/02/23/pelantikan-pengurus-HIMPAUDI-dan-seminar-peningkatankualitas-manajemen-lembaga/. Pelantikan pengurus HIMPAUDI dan Seminar Peningkatan kualitas Manajemen Lembaga

http://himpaudi-jawabarat.or.id/read/uncategorized/11/kilas-balik-himpaudi/. Kilas Balik HIMPAUDI. http://www.beritaindonesia.co.id/daerah/berprestasi-di-tengah-kesederhanaan. 226 Anak Ikut Festival PAUD

http://www.kotabogor.go.id/index.php?option=com content\&task=view\&id=4965\&Itemid=1. Pengurus HIMPAUDI Kecamatan Se Kota Bogor Dilantik http://himpaudijateng.wordpress.com/humas/. Kinerja bintang bidang HUMAS http://www.portalmalang.web.id/profil/mike-s-arifin-sosok-di-balik-suksesnya-HIMPAUDI-raih-juara-inasional.html diunduh 29 Juli 2010. Sosok Di Balik Seuksenya HIMPAUDI Kota Malang.

http://HIMPAUDI-jawabarat.or.id/read/news/49/pemantapan-strategi-HIMPAUDI-jabar/. Pemantapan Strategi HIMPAUDI Jabar http://bataviase.co.id/node/417530. 44,5\% Anak Usia Dini tak Terlayani Pendidikan http://paudpandanwangi.wordpress.com/2007/12/08/pelatihan-pengelolaan-data-online-bagiHIMPAUDI-se-jawa-tengah/. Pelatihan Pengelolaan Data Online Bagi Pengurus HIMPAUDI http://bengkalis.go.id/sajian_berita.php?link_atirebdi=682 . PAUD Bengkalis Raih Juara II Gerak dan Lagu http://paudnaelulmuna.com/search/HIMPAUDI+garut. FINGER PAINTING (Melukis Dengan Jari) Peraturan Menteri Pendidikan Nasional Republik Indonesia Nomor 19 tahun 2005 tentang Standar Nasional Pendidikan

Peraturan Menteri Pendidikan Nasional Republik Indonesia Nomor 58 tahun 2009 tentang Standar PAUD

Pusat Penelitian Kebijakan dan Inovasi Pendidikan. (2010). Kontribusi Pemerintah Daerah dalam Perintisan dan Penguatan PAUD. Jakarta: Kemendiknas.

Undang-Undang Republik Indonesia Nomor 20 Tahun 2003 tentang Sistem Pendidikan Nasional. Undang-Undang Republik Indonesia Nomor 14 Tahun 2005 tentang Guru dan Dosen. Undang-Undang Republik Indonesia Nomor 20 Tahun 2005 tentang Sistem Pendidikan Nasional. 